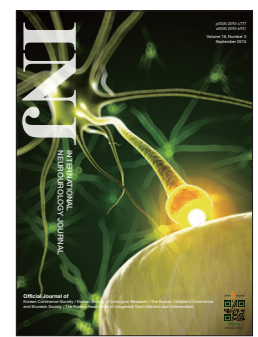

\title{
Is There a Relationship Between Pelvic Organ Prolapse and Tissue Fibrillin-1 Levels?
}

\author{
Ayla Eser ${ }^{1}$, Eylem Unlubilgin ${ }^{2}$, Fatih Hizli ${ }^{3}$, Muradiye Acar ${ }^{4}$, Zeynep Kamalak ${ }^{5}$, Aydin Kosus ${ }^{1}$, Nermin Kosus ${ }^{1}$, Deniz Hizli ${ }^{1}$, \\ Esra Gunduz ${ }^{4}$ \\ ${ }^{1}$ Department of Obstetrics and Gynecology, Turgut Ozal University Medical School, Ankara, Turkey \\ ${ }^{2}$ Department of Obstetrics and Gynecology, Etlik Zubeyde Hanim Training and Research Hospital, Ankara, Turkey \\ ${ }^{3}$ Department of Urology, Dr Abdurrahman Yurtaslan Oncology Training and Research Hospital, Ankara, Turkey \\ ${ }^{4}$ Department of Medical Genetics, Turgut Ozal University Medical School, Ankara, Turkey \\ ${ }^{5}$ Department of Obstetrics and Gynecology, Nenehatun Maternity Hospital, Erzurum, Turkey
}

Purpose: Pelvic organ prolapse is a multifactorial disorder in which extracellular matrix defects are implicated. Fibrillin-1 level is reduced in stress urinary incontinence. In Marfan syndrome, which is associated with mutations in Fibrillin-1, pelvic floor disorders are commonly observed. We hypothesize that Fibrillin-1 gene expression is altered in pelvic organ prolapse.

Methods: Thirty women undergoing colporrhaphy or hysterectomy because of cystocele, rectocele, cystorectocele, or uterine prolapse were assigned to a pelvic prolapse study group, and thirty women undergone hysterectomy for nonpelvic prolapse conditions were assigned to a control group. Real-time polymerase chain reaction was conducted on vaginal tissue samples to measure the expression of Fibrillin-1. Expression levels were compared between study and control groups by Mann-Whitney $\mathrm{U}$ test with Bonferroni revision.

Results: Fibrillin-1 gene expression was not significantly lower in the study group than in the control group. Similarly, no significant correlation between Fibrillin- 1 levels and grade of pelvic prolapse was found. Age over 40 years $(\mathrm{P}=0.018)$ and menopause $(\mathrm{P}=0.027)$ were both associated with reduced Fibrillin-1 levels in the pelvic prolapse group, whereas the delivery of babies weighing over 3,500 $\mathrm{g}$ at birth was associated with increased Fibrillin-1 expression $(\mathrm{P}=0.006)$.

Conclusions: The results did not indicate a significant reduction in Fibrillin-1 gene expression in pelvic prolapse disorders; however, reduced Fibrillin-1 may contribute to increased pelvic organ prolapse risk with age and menopause. Increased Fibrillin-1 gene expression may be a compensatory mechanism in cases of delivery of babies with high birth weight. Further studies are needed for a better understanding of these observations.

Keywords: Extracellular Matrix; Fibrillin; Pelvic Organ Prolapse

- Fund Support: This study was funded by the Turgut Ozal University, Ankara, Turkey.

- Research Ethics: The study was approved by Etlik Zubeyde Hanim Education and Research Hospital Ethical Committee and complied with the

Helsinki Declaration, 2011.

- Conflict of Interest: No potential conflict of interest relevant to this article was reported.

\section{INTRODUCTION}

Pelvic organ prolapse (POP) is a common pelvic floor disorder
[1]. The lifetime cumulative risk of POP has been estimated at $12.6 \%$ for adult women, with the risk increasing with age [2]. The etiology of POP is complex and multifactorial, and epide-

Corresponding author: Ayla Eser (iD http://orcid.org/0000-0002-7897-3481 Department of Obstetrics and Gynecology, Turgut Ozal University School of Medicine, Hosdere Cad. No:145-147 Y.Ayranci, Ankara 06560, Turkey E-mail: aylaacar76@yahoo.com.tr / Tel: +90-312-409-8888 / Fax: +90-312-409-8800 Submitted: May 24, 2015 / Accepted after revision: July 17, 2015 
miological studies suggest that multiple pathologies contribute to full anatomical loss. The mechanisms underlying pelvic floor support failure remain poorly understood; however, studies in both humans and animals implicate defects in the extracellular matrix (ECM) or fibrous connective tissue causing reduced tissue strength and defective repair [3]. The ECM of the pelvic floor, which is termed the endopelvic fascia, is responsible for maintaining the position of organs adjacent to the vagina.

The largest structures in the ECM are elastic fibers, which consist of a core of elastin, which is a cross-linked polymer of tropoelastin, supported on a lattice of microfibrils [4]. The elastic fibers enable tissue stretching. Microfibril proteins such as fibrillins and fibulins play an essential role in the assembly of elastic fibers. Fibrillins, which have three known forms Fibrillin-1, Fibrillin-2, and Fibrillin-3, are major structural elements of microfibrils [5-7]. Mutation of the Fibrillin-1 gene is the cause of Marfan syndrome, and POP is more prevalent in women with this disease [8]. Fibrillin-1 gene expression is reduced in women with stress urinary incontinence (SUI) [9], a pelvic floor dysfunction that is frequent feature of POP [1]. Reduction in other ECM proteins levels that interact with Fibrillin-1, such as fibulin- 5 and the small leucine-rich repeat proteoglycan (SLPR) decorin, has been observed in POP [10].

However, none of the studies to date have evaluated the relationship between Fibrillin-1 gene expression and POP. The present study is aimed at investigating the altered expression of the Fibrillin-1 gene in POP, by examining the differences in Fibrillin-1 expression between women with POP and those with no history of POP.

\section{MATERIALS AND METHODS}

The study was carried out at the Obstetrics and Gynecology Departments of 3 different hospitals: Turgut Ozal University Hospital in Ankara, Etlik Zubeyde Hanim Education and Research Hospital in Ankara, and Nenehatun Maternity Hospital in Erzurum, Turkey, between January and October 2013.

The study was approved by Etlik Zubeyde Hanim Education and Research Hospital Ethical Committee and complied with the Helsinki Declaration, 2011. Informed consent was obtained from all participants before the start of the study.

\section{Patients}

In total, 60 women, 30 women in the POP group and 30 women in the control group, matched for age, parity, and body mass index (BMI) were included in the study. Demographic characteristics of the patients are shown in Table 1. Women in the POP group had undergone colporrhaphy and/or vaginal hysterectomy for POP. The women in the control group had undergone total abdominal hysterectomy for other benign conditions. The median age of the POP patients was 45.5 years (range, $27-71$ years); 12 patients were pre- and 18 were postmenopausal and the median parity was 3 (range, $1-5$ ). The median age of the control patients was 47 years (range, 26-53 years); 3 patients were pre- and 27 were postmenopausal and the median parity was 2 (range, 1-5). Women with a history of endometriosis, gynecologic malignancies, pelvic inflammatory conditions, connective tissue disorders, emphysema, prior pelvic surgery, SUI, or diseases requiring systemic glucocorticoid treatment were excluded from

Table 1. Demographic characteristics of women in study and control groups

\begin{tabular}{lccc}
\hline Characteristic & Study group $(\mathrm{n}=30)$ & Control group $(\mathrm{n}=30)$ & P-value \\
\hline Age $(\mathrm{yr})$ & $45.5(27-71)$ & $47(26-53)$ & 0.899 \\
Parity $(\mathrm{n})$ & $3(1-5)$ & $2(1-5)$ & 0.324 \\
Body mass index $\left(\mathrm{kg} / \mathrm{m}^{2}\right)$ & $28.5(23-39)$ & $29.3(23-45)$ & 0.221 \\
Vaginal deliveries (n) & $1(1-3)$ & $1(1-3)$ & 0.352 \\
Delivery weight (g) & $3,525(3,200-3,800)$ & $3,400(2,700-4,750)$ & 0.339 \\
Menopause, $\mathrm{n}(\%)$ & & & $0.008^{*}$ \\
Yes & $18(60)$ & $27(90)$ & $0.009^{*}$ \\
No & $12(40)$ & $0(0-6)$ & 0.114 \\
Postmenopausal period (yr) & $0(0-26)$ & $0.085(0.010-0.439)$ & \\
Fibrillin-1 level & $0.066(0.005-0.429)$ & & \\
\hline
\end{tabular}

Values are presented as median (range) unless otherwise indicated.

${ }^{\star} \mathrm{P}<0.05$ was considered statistically significant. 
the study. All participants underwent a gynecological examination. Pelvic support was assessed by means of a physical exam to confirm support loss with motion and/or prolapse. The degree of descent was graded according to the POP quantification (POPQ) system [11] in both POP and control subjects. Neither premenopausal nor postmenopausal women had received hormonal therapy for at least 12 months prior to the study.

\section{Biopsies}

During surgery, periurethral (5 $\mathrm{mm}$ from the urethral orifice) and full-thickness biopsies of the vaginal wall were obtained, including mucosal and submucosal tissues $(6 \mathrm{~mm}$ in diameter and $10 \mathrm{~mm}$ in depth). This biopsy site has been demonstrated to be representative of the endopelvic fascia [12]. Biopsies were immediately transferred to liquid nitrogen and stored at $-70^{\circ} \mathrm{C}$ until further analysis.
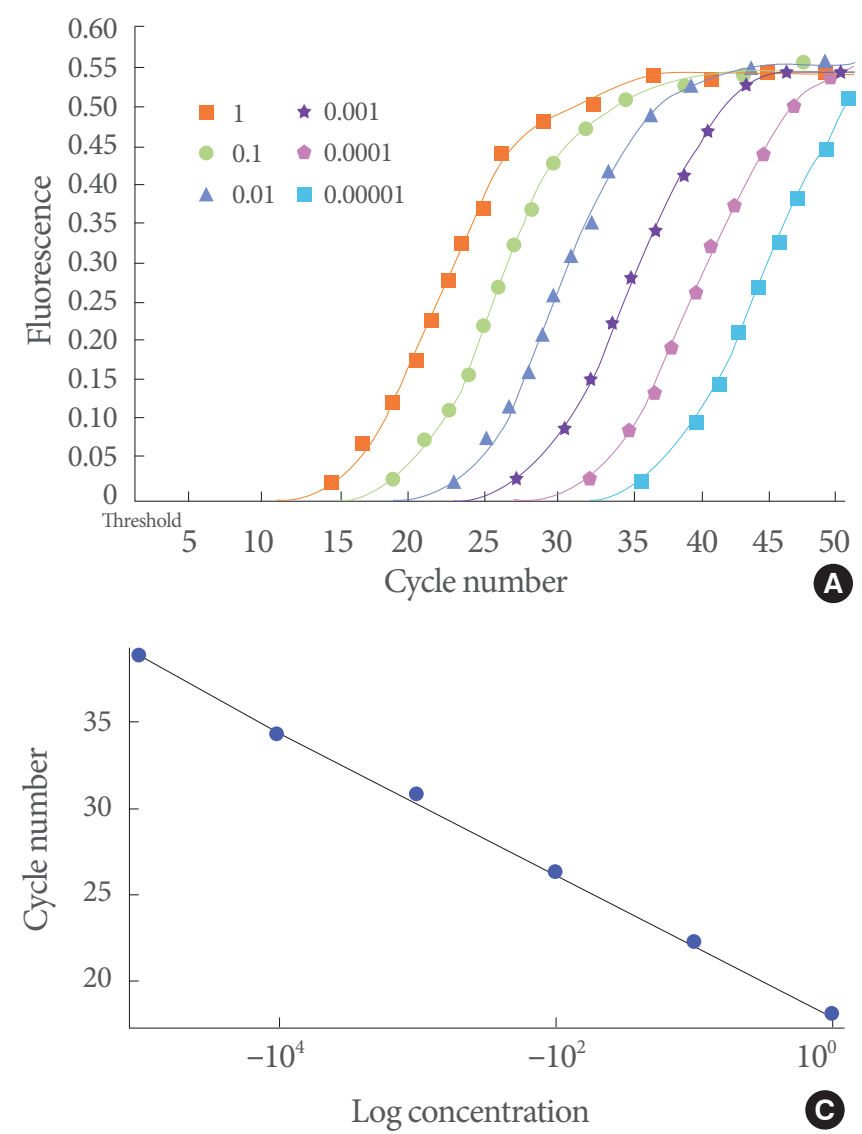

\section{RNA Extraction and Quantitative Real-Time Polymerase Chain Reaction}

Total RNA was extracted from tissues by using TRIzol reagent (Life Technologies, Carlsbad, CA, USA) according to the manufacturer's instructions. RNA concentration was measured and purity was assessed by a NanoDrop spectrophotometer (Thermo Fisher Scientific Inc., Wilmington, DE, USA). One microgram of the RNA sample was then transcribed into cDNA by using the RevertAid First Strand cDNA Synthesis Kit (Thermo Fisher Scientific, Vilnius, Lithuania) and oligo(dT) primers.

For quantitative real-time polymerase chain reaction (qRTPCR), cDNA samples were amplified by Rotor-Gene Q RealTime PCR (QIAGEN, Heidelberg, Germany) by using the QuantiTect SYBR Green PCR kit (QIAGEN). PCR primer sequences for Fibrillin-1 mRNA were as follows: Fibrillin-1 RAS2 5'-TGACTGGCCCACACGTGCATAG-3' (sense) and Fibril-
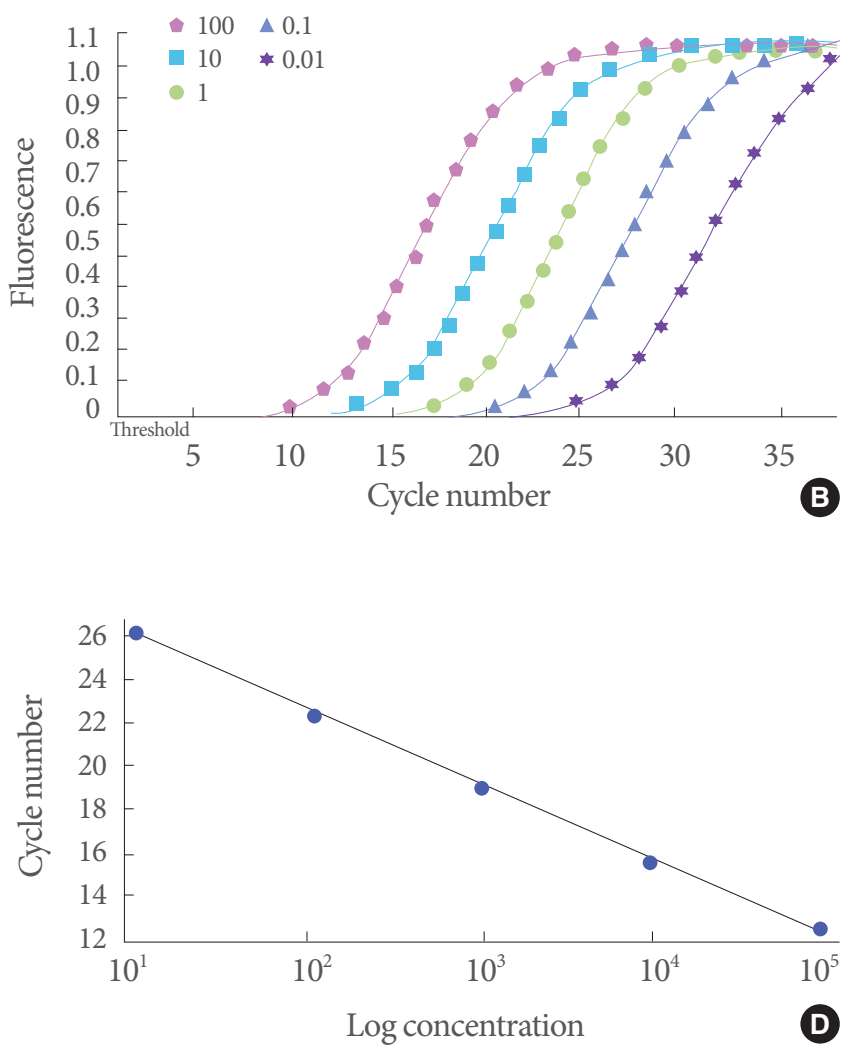

Fig. 1. Amplification plots of Fibrillin-1 mRNA (A) and housekeeping $\beta$-actin mRNA (B). Serial dilutions of Fibrillin- 1 and $\beta$-actin cDNA plasmids were prepared and amplification was performed by quantitative real-time polymerase chain reaction. For each dilution, fluorescence is plotted against the cycle number. Log concentration and cycle numbers of each dilution are shown. Serial dilutions of Fibrillin-1 and $\beta$-actin cDNA plasmids were prepared and amplification was performed. Log concentrations of Fibrillin-1 mRNA (C) and $\beta$-actin mRNA (D) were plotted against the cycle number. 
lin-1 RAS2 5' - TGACATTGACCCCTTGTTGACAGGA-3' (antisense). Fibrillin-1 gene expression was normalized to that of the housekeeping gene $\beta$-actin, by using primers $5^{\prime}$ - GGCCAACCGCGAGAAGATGAC-3' (sense) and 5'-GCTCGTAGCTCTTCTCCAGGG-3' (antisense). Total reaction volume of qRT-PCR was $50 \mu \mathrm{L}$, containing $25 \mu \mathrm{L}$ of SYBR Green mix, 1 $\mu \mathrm{L}$ of each $20 \mathrm{pmol} / \mu \mathrm{L}$ primer, $5 \mu \mathrm{L}$ of cDNA, and nuclease-free water up to a total volume of $50 \mu \mathrm{L}$. Samples were denatured at $95^{\circ} \mathrm{C}$ for 15 minutes followed by 40 cycles of denaturing, annealing, and extension at $95^{\circ} \mathrm{C}$ for 15 seconds, $60^{\circ} \mathrm{C}$ for $30 \mathrm{sec}$ onds, and $72^{\circ} \mathrm{C}$ for 30 seconds, respectively. Characteristic melting curves were obtained at the end of the amplification by cooling to $65^{\circ} \mathrm{C}$ for 15 seconds and then to $40^{\circ} \mathrm{C}$ for a further 30 seconds. Serial 10-fold dilutions were prepared from known quantities of $\beta$-actin and Fibrillin-1 PCR products to be used as standards to measure expression level of the unknown samples.

Data were analyzed using the Rotor-Gene Q Series Software 2.1.0 (Qiagen, Heidelberg, Germany) and expression levels were calculated by the standard curve method. Values were normalized to the level of $\beta$-actin for each sample (Fig. 1).

\section{Statistical Analysis}

SPSS ver. 16.0 (SPSS Inc., Chicago, IL, USA) was used for statistical analysis. The compatibility of the data with normal distribution was assessed graphically and by the Shapiro-Wilk test. In order to represent continuous data, median (range) was used for nonnormally distributed parameters, and number and percentage for categorical data. In order to compare data from three independent groups, the Kruskal-Wallis test was used for nonnormally distributed data. The Mann-Whitney test with Bonferroni correction was used for comparison between two sets of data established as significant by the Kruskal-Wallis test. Correlation between parameters was assessed using Spearman rank correlation coefficient. $\mathrm{P}<0.05$ was considered statistically significant.
Statistical power analysis showed that at least 59 patients were needed to achieve $85 \%$ power when alpha error was set to 0.05 , beta error to 0.20 , and effect size to 0.35 .

\section{RESULTS}

In total, 60 women were included in the study: 30 women in the POP group and 30 women in the control group. The median age of the subjects was 45.5 years (range, 27-71 years). Demographic features of patients are shown in Table 1. There was no statistical difference in age, parity, BMI, or delivery weight between the study and control groups. Menopause ratio and median time after menopause were significantly higher in the pelvic prolapse group $(\mathrm{P}<0.05)$ (Table 1$)$. Surgery indications are shown in Table 2.

There was no statistically significant difference in median Fibrillin-1 levels between the study and control groups (Table 1). Correlation analysis revealed a moderate negative correlation between Fibrillin-1 expression and age, and a moderate positive correlation between Fibrillin-1 expression and delivery weight in the POP group (Rho $=-0.520, \mathrm{P}=0.006$ and $\mathrm{Rho}=0.413$, $\mathrm{P}=0.036$, respectively) (Table 3 ). No significant correlations

Table 2. Surgery indications

\begin{tabular}{lc}
\hline Group & No. $(\%)$ \\
\hline Study $(\mathrm{n}=30)$ & \\
Uterine prolapse & $6(20.0)$ \\
Rectocele & $3(10.0)$ \\
Cystorectocele & $18(60.0)$ \\
Cystocele & $3(10.0)$ \\
Control $(\mathrm{n}=30)$ & \\
DUB & $10(33.3)$ \\
Endometrial hyperplasia & $1(3.3)$ \\
Myoma uteri & $19(63.3)$ \\
\hline
\end{tabular}

DUB, dysfunctional uterine bleeding.

Table 3. Correlation between Fibrillin-1 expression and pelvic relaxation stages/demographic characteristics

\begin{tabular}{|c|c|c|c|c|c|c|c|c|c|c|}
\hline Fibrillin-1 & $\begin{array}{l}\text { Postmenopausal } \\
\text { period }\end{array}$ & Age & $\begin{array}{l}\text { Body mass } \\
\text { index }\end{array}$ & Gravidity & Parity & $\begin{array}{l}\text { Vaginal } \\
\text { delivery }\end{array}$ & $\begin{array}{c}\text { Delivery } \\
\text { weight }\end{array}$ & $\begin{array}{l}\text { Cystocele } \\
\text { stage }\end{array}$ & $\begin{array}{l}\text { Rectocele } \\
\text { stage }\end{array}$ & $\begin{array}{c}\text { Cystorectocele } \\
\text { stage }\end{array}$ \\
\hline \multicolumn{11}{|l|}{ Case } \\
\hline Rho & -0.420 & $-0.520^{\mathrm{a})}$ & -0.140 & -0.188 & -0.332 & 0.243 & $0.413^{\mathrm{a})}$ & -0.037 & 0.101 & 0.038 \\
\hline $\mathrm{P}$-value & $0.032^{*}$ & $0.006^{*}$ & 0.496 & 0.358 & 0.097 & 0.232 & $0.036^{*}$ & 0.858 & 0.625 & 0.852 \\
\hline \multicolumn{11}{|l|}{ Control } \\
\hline Rho & 0.051 & 0.015 & 0.023 & -0.057 & -0.009 & -0.110 & -0.241 & - & - & - \\
\hline $\mathrm{P}$-value & 0.794 & 0.939 & 0.905 & 0.770 & 0.965 & 0.569 & 0.207 & - & - & - \\
\hline
\end{tabular}

${ }^{\star} \mathrm{P}<0.05$ was considered statistically significant. ${ }^{\text {a) }}$ Rho was considered as significant correlation. 
were observed with respect to these parameters in the control group (Table 3 ).

Within the pelvic prolapse group, Fibrillin-1 expression was significantly lower in patients over 40 years old and in those

Table 4. Association between demographic characteristics and Fibrillin-1 ratio in the pelvic prolapse group

\begin{tabular}{|c|c|c|c|}
\hline Demographic attribute & No. & Fibrillin-1 & $\mathrm{P}$-value \\
\hline Age (yr) & & & $0.018^{*}$ \\
\hline$<40$ & 15 & $0.075(0.005-0.429)$ & \\
\hline$\geq 40$ & 15 & $0.035(0.015-0.103)$ & \\
\hline Parity & & & 0.083 \\
\hline 2 & 12 & $0.081(0.0345-0.429)$ & \\
\hline 3 & 10 & $0.036(0.021-0.092)$ & $0.043^{\star, \mathrm{a})}$ \\
\hline 4 & 4 & $0.072(0.064-0.075)$ & \\
\hline$\geq 5$ & 4 & $0.015(0.005-0.056)$ & $0.049^{*, \mathrm{~b})}$ \\
\hline Vaginal deliveries & & & 0.403 \\
\hline 1 & 24 & $0.047(0.005-0.429)$ & \\
\hline 2 & 4 & $0.080(0.067-0.084)$ & \\
\hline 3 & 2 & $0.064(0.049-0.079)$ & \\
\hline Body mass index $\left(\mathrm{kg} / \mathrm{m}^{2}\right)$ & & & 0.782 \\
\hline$<25$ & 6 & $0.077(0.021-0.103)$ & \\
\hline $25-30$ & 14 & $0.058(0.015-0.429)$ & \\
\hline$\geq 30$ & 10 & $0.056(0.005-0.092)$ & \\
\hline Delivery weight (g) & & & $0.006^{*}$ \\
\hline$<3,500$ & 10 & $0.029(0.005-0.075)$ & \\
\hline$\geq 3,500$ & 20 & $0.078(0.021-0.429)$ & \\
\hline Menopause (n) & & & $0.027^{*}$ \\
\hline Yes & 18 & $0.032(0.015-0.103)$ & \\
\hline No & 12 & $0.076(0.005-0.429)$ & \\
\hline Postmenopausal period (yr) & & & 0.889 \\
\hline$<5$ & 2 & $0.034(0.021-0.047)$ & \\
\hline$\geq 5$ & 12 & $0.032(0.015-0.103)$ & \\
\hline
\end{tabular}

Values are presented as median (range).

${ }^{\star} \mathrm{P}<0.05$ was considered statistically significant. ${ }^{\text {a) }}$ Comparing parity 2 and $3 .{ }^{\text {b) }}$ Comparing parity 2 and 5 . with menopause, and significantly higher in patients who had delivered infants with birth weight of over 3,500 $\mathrm{g}$ (Table 4). Fibrillin-1 levels were significantly decreased after the third parity, although the significance levels were marginal $(\mathrm{P}=0.049)$ (Table 4). Other demographic attributes were not associated with significantly altered Fibrillin-1 expression (Table 4 ). With respect to the type and POP-Q stage of pelvic prolapse, no statistically significant difference was observed in Fibrillin-1 expression between patients with 4th stage cystocele and those with other stages of cystocele and without prolapse (Table 5). There was no significant difference in Fibrillin-1 levels with respect to other types and prolapse stages (Table 5). With respect to age over 40 years and menopause, Fibrillin-1 levels were significantly lower

Table 5. Distribution of Fibrillin-1 values according to pelvic prolapse type

\begin{tabular}{lrcc}
\hline POP surgery & No. & Fibrillin-1 & P-value \\
\hline Only cystocele & 3 & $0.054(0.021-0.080)$ & 0.718 \\
Only rectocele & 3 & $0.077(0.015-0.098)$ & \\
Cystorectocele & 18 & $0.049(0.005-0.429)$ & \\
Cystocele, POP-Q stage & & & 0.294 \\
1 & 1 & $0.005(-)$ & \\
2 & 8 & $0.049(0.021-0.080)$ & \\
3 & 10 & $0.064(0.015-0.429)$ & \\
4 & 5 & $0.041(0.028-0.092)$ & \\
Rectocele, POP-Q stage & & & 0.304 \\
1 & 1 & $0.049(-)$ & \\
2 & 19 & $0.041(0.015-0.080)$ & \\
3 & 3 & $0.072(0.021-0.429)$ & \\
Uterine prolapse & & & 0.231 \\
$\quad$ Yes & 6 & $0.047(0.021-0.072)$ & \\
No & 22 & $0.075(0.005-0.429)$ & \\
\hline
\end{tabular}

Values are presented as median (range).

POP, pelvic organ prolapse; POP-Q, POP quantification.

Table 6. Decrease in Fibrillin-1 levels with age and menopause in POP group but not in control group subjects

\begin{tabular}{llll}
\hline Demographic attribute & \multicolumn{1}{c}{ Study group } & Control group & P-value \\
\hline Age $($ yr $)$ & & & $0.041(-)$ \\
$\quad<40$ & $0.075(0.005-0.429)$ & $0.085(0.010-0.439)$ & 0.400 \\
$\geq 40$ & $0.035(0.015-0.103)$ & 0.552 & $0.026^{*}$ \\
P-value & $0.018^{*}$ & & $0.092(0.021-0.383)$ \\
Menopause (n) & & $0.080(0.010-0.439)$ & 0.501 \\
Yes & $0.032(0.015-0.103)$ & 0.866 &
\end{tabular}

Values are presented as median (range).

POP, pelvic organ prolapse.

${ }^{\star} \mathrm{P}<0.05$ was considered statistically significant. 
in the POP group compared to the control group (Table 6).

\section{DISCUSSION}

This case-control study was undertaken to investigate the differences in Fibrillin-1 gene expression between women with and without POP. The results indicated no statistical difference between the study and control groups.

There are substantial indications in the literature to suggest that alterations in microfibril components, particularly in Fibrillin-1, are relevant in pelvic prolapse and POP. Fibrillin-1 gene expression is reduced in SUI, a pelvic floor disorder often associated with POP [9]. Furthermore, POP is prevalent in Marfan syndrome [8]. Additionally, Fibrillin-1 mutation and/or reduced synthesis or deposition is a marker for other connective tissue disorders including stiff skin syndrome, Weill-Marchesani syndrome, aortic aneurysm and dissection, and lens luxation [1315]. With respect to other microfibril components in POP, studies have suggested that the expression of fibulin- 5 is reduced in women with POP [10]. Additionally, POP has been demonstrated to occur in fibulin-5 knockout mice [16]. Fibulin-5 plays a role in the organization of elastic fiber assembly on the microfibril lattice by acting as an adapter protein linking components such as Fibrillin-1 [17]. Fiber assembly involves cross-linking of collagen and elastic fibers, for which SLPRs such as decorin, lumican, and fibromodulin are important [10]. In particular, decorin-Fibrillin-1 interactions are crucial for the assembly of elastic fibers [10,18]. Additionally, decorin mediates Fibrillin-1 protein expression [19]. Reduced expression of decorin and other SLPRs has been observed in women with POP [10].

The data described above strongly suggest that patients with POP may show altered Fibrillin-1 levels; however, our results showed that there was no statistically significant reduction in Fibrillin-1 gene expression in women with pelvic prolapse disorders, which is consistent with findings of other studies [10]. Established risk factors for prolapse include increasing age and higher parity, the number of vaginal deliveries, giving birth to infants of high birth weight, presence of menopause, and time after menopause [1,20,21]. Analysis of the pelvic prolapse group in our study with respect to these parameters confirmed that Fibrillin-1 levels were significantly reduced in women over 40 years of age and in women who had experienced menopause. This was not observed in the control group, suggesting that the reduction in Fibrillin-1 was not necessarily a result of aging or menopause per se. Fibrillin is the major constituent of microfi- brils, which support elastic fibers of the ECM that enable tissue stretching [4-7]. Therefore, it is not entirely unreasonable to suggest that a reduction in Fibrillin-1 levels after menopause may make women more vulnerable to POP because of potential negative effects on pelvic floor integrity. Alternatively, the presence of POP in addition to age over 40 years or presence of menopause may cause a reduction in Fibrillin-1. Thus, these findings may have clinical significance in the context of the increased risk of POP with advancing age and menopause. Further studies in larger groups of subjects would be helpful in clarifying whether there is a difference in Fibrillin-1 levels, which becomes more pronounced with age and/or menopause, between women with and without POP. We found that, strictly, there was no significant difference between the groups; however, our data were at the borderline of significance $(\mathrm{P}=0.066)$. Studies in larger cohorts would be helpful for clarification.

In contrast, women who had delivered babies with birth weight of over 3,500 g showed an unexpected higher expression of Fibrillin-1. High birth weight is a risk factor for the development of POP, and it has been suggested that elastic fibers are critical in maintaining vaginal wall support. Pelvic floor disorders, such as POP, are associated with increased expression of ECM proteases in both humans and in mouse models of POP, including matrix metalloprotease-9 (MMP-9), which may cause reduced fibrillin protein levels $[22,23]$. The observed increase in Fibrillin-1 gene expression may represent a mechanism to compensate for effects of MMP-9 and other proteases on elastic fibers in POP. However, this is speculative, and a definitive explanation of the increase in Fibrillin-1 gene expression would require further studies on larger samples of patients.

Although we carried out a power analysis to determine appropriate sample size, our study was limited by the relatively small number of subjects. This may have contributed to the lack of statistically meaningful differences in Fibrillin-1 expression between the control and pelvic prolapse groups. Therefore, larger studies with more patients are necessary. Our study did yield results with potential clinical relevance in terms of indicating a possible role for fibrillin in women aged over 40 years, particularly in those who have experienced menopause, as the presence of menopause was itself significantly associated with POP. Furthermore, Fibrillin-1 levels may be of significance in women with POP who have delivered babies with birth weight over 3,500 g. Currently, fibrillin is not a marker for predicting pelvic prolapse development. However, fibrillin levels may be indicative of the risk of pelvic prolapse development when con- 
sidered together with factors such as age and menopause stage. Larger studies with more patients would be needed to confirm the potential role of Fibrillin-1 in POP development.

\section{ACKNOWLEDGEMENTS}

The present study was awarded third place in POSTER presentations at the "13th Gynecology and Obstetrics National Congress" held at the Antalya Belek Kaya Plazzo Golf Resort Hotel on May 11-15, 2015.

\section{REFERENCES}

1. Jelovsek JE, Maher C, Barber MD. Pelvic organ prolapse. Lancet 2007;369:1027-38.

2. Wu JM, Matthews CA, Conover MM, Pate V, Jonsson Funk M. Lifetime risk of stress urinary incontinence or pelvic organ prolapse surgery. Obstet Gynecol 2014;123:1201-6.

3. Kerkhof MH, Hendriks L, Brolmann HA. Changes in connective tissue in patients with pelvic organ prolapse: a review of the current literature. Int Urogynecol J Pelvic Floor Dysfunct 2009;20:461-74.

4. Sandberg LB, Weissman N, Gray WR. Structural features of tropoelastin related to the sites of cross-links in aortic elastin. Biochemistry 1971;10:52-6.

5. Ramirez F, Sakai LY, Dietz HC, Rifkin DB. Fibrillin microfibrils: multipurpose extracellular networks in organismal physiology. Physiol Genomics 2004;19:151-4.

6. Sakai LY, Keene DR, Engvall E. Fibrillin, a new 350-kD glycoprotein, is a component of extracellular microfibrils. J Cell Biol 1986;103(6 Pt 1):2499-509.

7. Zhang H, Apfelroth SD, Hu W, Davis EC, Sanguineti C, Bonadio J, et al. Structure and expression of fibrillin-2, a novel microfibrillar component preferentially located in elastic matrices. J Cell Biol 1994;124:855-63.

8. Carley ME, Schaffer J. Urinary incontinence and pelvic organ prolapse in women with Marfan or Ehlers Danlos syndrome. Am J Obstet Gynecol 2000;182:1021-3.

9. Soderberg MW, Byström B, Hammarström M, Malmstrom A, Ekman-Ordeberg G. Decreased gene expression of fibrillin-1 in stress urinary incontinence. Neurourol Urodyn 2010;29:476-81.

10. Soderberg MW, Bystrom B, Kalamajski S, Malmstrom A, EkmanOrdeberg G. Gene expressions of small leucine-rich repeat proteoglycans and fibulin-5 are decreased in pelvic organ prolapse. Mol Hum Reprod 2009;15:251-7.
11. Bump RC, Mattiasson A, Bo K, Brubaker LP, DeLancey JO, Klarskov $\mathrm{P}$, et al. The standardization of terminology of female pelvic organ prolapse and pelvic floor dysfunction. Am J Obstet Gynecol 1996;175:10-7.

12. DeLancey JO. Structural support of the urethra as it relates to stress urinary incontinence: the hammock hypothesis. Am J Obstet Gynecol 1994;170:1713-20.

13. Sengle G, Tsutsui K, Keene DR, Tufa SF, Carlson EJ, Charbonneau $\mathrm{NL}$, et al. Microenvironmental regulation by fibrillin-1. PLoS Genet 2012;8:e1002425.

14. Francke U, Berg MA, Tynan K, Brenn T, Liu W, Aoyama T, et al. A Gly1127Ser mutation in an EGF-like domain of the fibrillin-1 gene is a risk factor for ascending aortic aneurysm and dissection. Am J Hum Genet 1995;56:1287-96.

15. Sachdev N, Wakefield D, Coroneo MT. Lens dislocation in Marfan syndrome and UV-B light exposure. Arch Ophthalmol 2003;121:585.

16. Drewes PG, Yanagisawa H, Starcher B, Hornstra I, Csiszar K, Marinis SI, et al. Pelvic organ prolapse in fibulin-5 knockout mice: pregnancy-induced changes in elastic fiber homeostasis in mouse vagina. Am J Pathol 2007;170:578-89.

17. Freeman LJ, Lomas A, Hodson N, Sherratt MJ, Mellody KT, Weiss AS, et al. Fibulin-5 interacts with fibrillin-1 molecules and microfibrils. Biochem J 2005;388(Pt 1):1-5.

18. Trask BC, Trask TM, Broekelmann T, Mecham RP. The microfibrillar proteins MAGP-1 and fibrillin-1 form a ternary complex with the chondroitin sulfate proteoglycan decorin. Mol Biol Cell 2000;11:1499-507.

19. Schaefer L, Tsalastra W, Babelova A, Baliova M, Minnerup J, Sorokin L, et al. Decorin-mediated regulation of fibrillin-1 in the kidney involves the insulin-like growth factor-I receptor and Mammalian target of rapamycin. Am J Pathol 2007;170:301-15.

20. Abramowitch SD, Feola A, Jallah Z, Moalli PA. Tissue mechanics, animal models, and pelvic organ prolapse: a review. Eur J Obstet Gynecol Reprod Biol 2009;144 Suppl 1:S146-58.

21. Word RA, Pathi S, Schaffer JI. Pathophysiology of pelvic organ prolapse. Obstet Gynecol Clin North Am 2009;36:521-39.

22. Wieslander CK, Rahn DD, McIntire DD, Acevedo JF, Drewes PG, Yanagisawa H, et al. Quantification of pelvic organ prolapse in mice: vaginal protease activity precedes increased MOPQ scores in fibulin 5 knockout mice. Biol Reprod 2009;80:407-14.

23. Budatha M, Roshanravan S, Zheng Q, Weislander C, Chapman SL, Davis EC, et al. Extracellular matrix proteases contribute to progression of pelvic organ prolapse in mice and humans. J Clin Invest 2011;121:2048-59. 